DOI: https://doi.org/10.31933/jimt.v2i3

Received: 17 November 2020, Revised: 25 Desember 2020, Publish: 16 Februari 2021

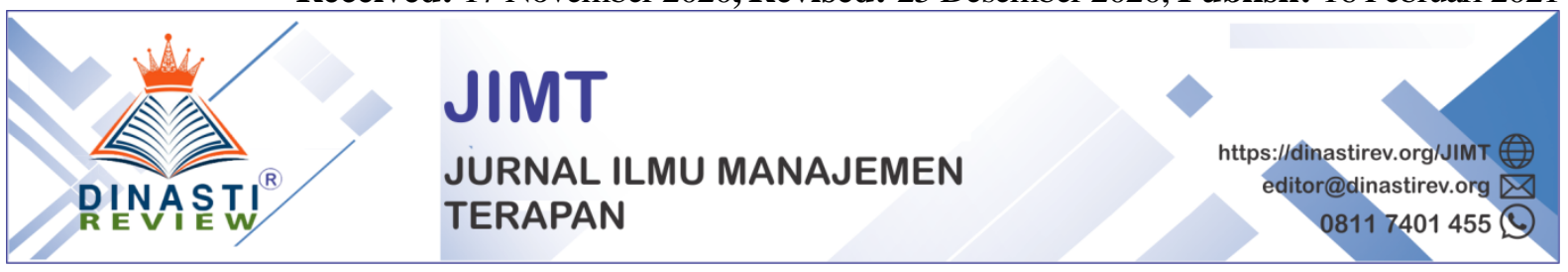

\title{
FAKTOR YANG MEMPENGARUHI MANAJEMEN LEMBAGA PENDIDIKAN ISLAM: SISTEM PENDANAAN
}

\author{
Armawati Armawati ${ }^{1}$, Kemas Imron Rosadi ${ }^{2}$ \\ ${ }^{1}$ Dr. Student Program at UIN STS Jambi, email; armawati217@gmail.com \\ ${ }^{2}$ Lecturer at Universitas UIN STS Jambi, email; kemasimronrosadi@uinjambi.ac.id \\ Corresponding Author: Armawati Armawati ${ }^{1}$
}

\begin{abstract}
Abstrak: Dalam kajian ini penulis mencoba mengangkat permasalah yang mempengaruhi manajemen lembaga pendidikan. Faktornya adalah sistem pendanaan. Pendanaan pendidikan Islam merupakan kegiatan yang berkaitan dengan memperoleh dana yang telah diperoleh dan bagaimana menggunakan dana tersebut untuk kepentingan sekolah agar tujuan pendidikan yang telah ditetapkan dapat berjalan secara efektif. Konsep biaya pendidikan adalah bahwa semua pengeluaran baik dalam bentuk moneter maupun non moneter merupakan ungkapan tanggung jawab semua pihak (yaitu masyarakat, orang tua dan pemerintah) terhadap perkembangan pendidikan, sehingga tujuan dan cita-cita yang telah ditetapkan dapat tercapai secara efektif dan efisien. Selain itu, biaya pendidikan harus ditarik dari berbagai sumber untuk pemeliharaan, pemantapan dan penataan administrasi agar biaya pendidikan dapat dilaksanakan secara efektif dan efisien.
\end{abstract}

Kata Kunci: Sistem, Pendanaan, Manajemen, Pendidikan Islam

\section{PENDAHULUAN}

Seiring berjalannya waktu Pendidikan Islam selalu mengalami perubahan. Dan tumbuh kembang pendidikan di Indonesia sangat erat kaitannya dengan kegiatan Islamisasi. Pendidikan Islam merupakan mediator, dan ajaran Islam dapat diterima oleh masyarakat. Melalui pendidikan tersebut, masyarakat Indonesia dapat memahami, menghayati dan mengamalkan ajaran Islam sesuai dengan ketentuan Alquran dan Sunnah.(Mochammad Arif Budiman, 2017). Namun, hingga saat ini pendidikan Islam di Indonesia masih menghadapi berbagai permasalahan yang tidak bisa diabaikan begitu saja. Dari segi tujuan, mata kuliah, tenaga pengajar, sarana dan prasarana, pendanaan, dan lain-lain, berbagai komponen pendidikan Islam masih menghadapi permasalahan yang mendasar, yang menyebabkan kualitas pendidikan Islam kurang memuaskan.

Masalah klasik yang masih melanda lembaga pendidikan Islam di negeri ini terutama terkait dengan dana pendidikan yang paling rendah. Ini mempengaruhi hampir semua komponen pendidikan lainnya (Romlah, 2016). Padahal, biaya pendidikan merupakan salah satu komponen investasi instrumental yang sangat penting dalam pendidikan sekolah dan 
pesantren. Dalam segala upaya untuk mencapai tujuan pendidikan, biaya dan pendanaan pendidikan memegang peranan penting.Hampir tidak ada pekerjaan pendidikan yang mengabaikan peran biaya, sehingga dapat dikatakan tanpa biaya proses pendidikan tidak dapat berjalan secara maksimal.

Memberikan pendidikan pada dasarnya mahal. Hal ini dikarenakan pengelolaan pendidikan sekolah dan madrasah dalam segala kegiatannya membutuhkan sarana dan prasarana untuk proses pengajaran, pelayanan, pelaksanaan program, serta kesejahteraan guru dan staf yang ada yang kesemuanya membutuhkan anggaran (Purnomo, 2015). Sehubungan dengan hal tersebut, setiap pengelola pendidikan Islam hendaknya memahami sejarah pembiayaan pendidikan Islam di Indonesia serta teori dan praktik pengelolaan pembiayaan pendidikan.

Biaya pendidikan merupakan bagian yang sangat penting dalam penyelenggaraan pendidikan. Bisa dikatakan tanpa dukungan dana, proses pendidikan tidak bisa berjalan. Dalam konteks perencanaan pendidikan, diperlukan pemahaman tentang anatomi dan permasalahan pendanaan pendidikan (Atmaja et al., 2016). Berdasarkan pemahaman tersebut, kebijakan pembiayaan pendidikan yang lebih tepat dan berkeadilan dapat dirumuskan untuk mencapai tujuan pendidikan, baik secara kuantitas maupun kualitas.

Berdasarkan latar belakang masalah di atas maka rumusan masalah artikel ini adalah untuk mereview teori pengaruh variabel independent terhadap variabel dependent seperti tertera di bawah ini:

1) Apakah sistem berpengaruh terhadap manajemen lembaga pendidikan Islam?

2) Apakah pendanaan berpengaruh terhadap manajemen lembaga pendidikan Islam?

\section{KAJIAN PUSTAKA}

\section{Manajemen Pendidikan Islam}

Kata manajemen berasal dari bahasa Inggris dari kata kerja "to manage" yang sinonimnya antara lain; "to hand" berarti mengurus, "to control" berarti memeriksa, "to guide" berarti memimpin.1 Dalam kamus istilah populer, kata manajemen mempunyai arti pengelolaan usaha, kepengurusan, ketatalaksanaan, penggunaan sumber daya secara efektif untuk mencapai sasaran yang di inginkan direksi (Kristiawan et al., 2017). Tujuan pendidikan dalam Al-Qur'an adalah membina manusia secara pribadi dan kelompok sehingga mampu menjalankan fungsinya sebagai hamba Allah dan khalifah-Nya guna membangun dunia ini sesuai dengan konsep yang ditetapkan oleh Allah (Kuntoro, 2019). Keberhasilan pelaksanaan penyelenggaraan pendidikan sesuai dengan tujuan tergantung pada proses manajerial yang terdapat di dalamnya.

Manajemen sebagai disiplin ilmu. Menurut ajaran Alquran dan Hadits, asas dan asas manajemen telah dijelaskan sebelumnya.Dibandingkan dengan teori-teori manajemen para ahli masa kini, bobotnya sama pentingnya, karena doktrin ini juga merupakan asas dan landasan manajemen dasar lainnya. Sebagai contoh dapat dikemukakan Al-Qur'an: Artinya:

\footnotetext{
${ }^{1}$ Saefullah, Manajemen Pendidikan Islam, Bandung: CV Pustaka Setia, 2014, hlm. 1
} 
"Dan janganlah kamu mengikuti apa yang kamu tidak mempunyai pengetahuan tentangnya. Sesungguhnya pendengaran, penglihatan dan hati, semuanya itu akan ditanya (diminta pertanggung jawabnya)".(Q.S. Al-Isra' ayat 36).

Makna manajemen sering diartikan sebagai ilmu, kiat dan professional. Manajemen diartikan sebagai ilmu karena merupakan suatu bidang ilmu pengetahuan yang secara sistematik berusaha memahami mengapa dan bagaimana orang bekerjasama (Madarik, 2018). Manajemen diartikan sebagai kiat karena manajemen mencapai sasaran melalui cara-cara dengan mengatur orang lain menjalankan tugasnya. Manajemen pendidikan merupakan kegiatan yang mengintegrasikan sumber daya pendidikan untuk mencapai tujuan pendidikan yang telah ditetapkan. Manajemen pendidikan adalah suatu sistem untuk mengelola dan membangun sumber daya pendidikan, seperti tenaga pendidik, peserta didik, masyarakat, kursus, dana, sarana dan prasarana pendidikan, manajemen, dan lingkungan. Pendapat lain adalah bahwa manajemen pendidikan mengacu pada pengerahan semua sumber daya pendidikan untuk mencapai tujuan pendidikan yang telah ditetapkan (Madarik, 2018)

Manajemen dalam pendidikan islam sudah banyak di telit oleh peneliti sebelumnya di antaranya adalah (Fadhli, 2017; Fattah, 2016; Hasibuan et al., 2018; Husaini, 2008; Kuntoro, 2019)

\section{Sistem}

Sistem adalah kumpulan dari elemen-elemen yang berinteraksi untuk mencapai suatu tujuan tertentu. Sistem ini menggambarkan suatu kejadian-kejadian dan kesatuan yang nyata, seperti tempat, benda dan orang-orang yang betul-betul ada dan terjadi (BARIDWAN, 2015). Sistem adalah rangkaian dari dua atau lebih komponen-komponen yang saling berhubungan, yang berinteraksi untuk mencapai suatu tujuan.Sebagian besar sistem terdiridari subsistem yang lebih kecil yang mendukung sistem yang lebih besar (Romney \& Steinbart, 2015). Sistem adalah salah satu pendekatan yang diperlukan agar manusia dapat memandang persoalan-persoalan dunia ini dengan lebih menyeluruh dan dengan demikian pengambilan keputusan dan pilihan aksi dapat dibuat lebih terarah kepada sumber-sumber persoalan yang akan mengubah sistem secara efektif (Hidayatno, 2016).

Selanjutnya salamun mengartikan bahwa sistem adalah sekumpulan elemen yang saling berhubungan antara satu dengan yang lainnya dan membentuk fungsi tertentu (Salamun, 2017). Ackoff mendefinisikan pada prinsipnya berpikir sistemik mengkombinasikan dua kemampuan berpikir, yaitru kemampuan berpikir analis dan berfikir sintesis (Ackoff, 1994). Kesisteman dalam pendidikan islam sudah banyak di telit ioleh peneliti sebelumnya di antaranya adalah (Hidayatno, 2016; Salamun, 2017; Sumarto, 2016; Syahminan, 2014).

\section{Pendanaan}

Pembiayaan sekolah adalah proses menggunakan pendapatan dan sumber daya yang tersedia untuk mendirikan dan menjalankan sekolah di berbagai wilayah geografis dan 
tingkat pendidikan yang berbeda, bidang politik pembiayaan sekolah dan pendidikan, program pendanaan pemerintah dan sekolah (Idris, 2008). Terkait manajemen. Beberapa istilah yang sering digunakan dalam pembiayaan sekolah yaitu pendapatan sekolah, pengeluaran sekolah, modal dan biaya saat ini. Dalam penggalangan dana sekolah, tidak ada satu cara terbaik untuk menggalang dana untuk semua sekolah, karena setiap sekolah memiliki kondisi yang berbeda-beda (Tedjawati, 2013).

Biaya dalam pendidikan meliputi biaya langsung (direct cost) dan biaya tidak langsung (Inderect Cost). Biaya langsung terdiri dari biaya-biaya yang dikeluarkan untuk keperluan pelaksanaan pengajaran dan kegiatan belajar siswa berupa pembelian alat-alat pelajaran, sarana belajar, biaya transportasi, gaji guru, baik yang dikeluarkan pemerintah, orang tua, maupun siswa sendiri. Sedangkan biaya tidak langsung berupa keuntungan yang hilang (oportunity cost) yang dikorbankan oleh siswa selama belajar (ARIFIN, 2017). Pasal 49 ayat 1 UU No. 20 tahun 2003 menyatakan alokasi dana pendidikan minimal 20\% dari APBN, dan $20 \%$ dari APBD selain gaji dan biaya pendidikan kedinasan. Pendanaandalam pendidikan islam sudah banyak di telit ioleh peneliti sebelumnya di antaranya adalah(Siti Zakiah Binti Ali \& Hairunnizam Wahid, 2014), (Tho'in, 2017), (Rahmah, 2016).

\section{METODE PENELITIAN}

Metode penelitian pada artikel ilmiah ini adalah metode kualitatif dengan pendekatan studi literatur(Library Research). Sumber yang dijadikan rujukan adalah buku-buku, artikel ilmiah online dari mendeley dan google scholar.

Metode penelitian artikel ilmiah ini adalah metode penelitian kepustakaan atau studi pustaka. Yakni mempelajari buku-buku sastra sesuai dengan teori-teori yang dibahas dalam topik artikel (Nasution, 2002; Suharsimi, 2013). Selain itu dibahas secara mendalam pada bagian berjudul "Literatur Terkait" atau Literature Reviewsebagai dasar pengusulan hipotesis, yang selanjutnya akan menjadi dasar perbandingan dengan hasil atau temuan yang diungkapkan dalam penelitian (Ali \& Limakrisna, 2013). Selain bersifat kepustakaan, penelitain ini juga bersifat kualitatif. Karena yang di hasilkan adalah bersifat deskriptif analitis. Yaitu memaparkan permasalahan secara apa adanya berdasarkan pada sumbersumber rujukan otoritatif dalam bidang pendidikan, sesuai teori yang di teliti (Suharsimi, 2013).

\section{HASIL DAN PEMBAHASAN}

\section{Pengaruh atau Hubungan antara variabel exogen terhadap variabel endogen.}

Dalam kajian artikel ini penulis menganalisis serta membahas mengenai variabelvariabel yang mempengaruhi lembaga pendidikan Islam yaitu variabel kesisteman, dan variabel pendanaan.

\section{Pengaruh / Hubungan Sistem Terhadap Manajemen Lembaga Pendidikan Islam}


Sistem memiliki pengaruh/ hubungan terhadap manajemen lembaga pendidikan islam. Pernyataan ini berdasarkan dari artikel-artikel hasil riset yang relevan dan telah di review. Di antaranya ialah (Mujilan, 2013), (Bangun et al., 2014), (Sulindawati \& Fathoni, 2010).

Suatu sistem terdiri dari banyak komponen yang saling berhubungan, artinya dapat bekerja sama membentuk satu kesatuan. Komponen sistem terdiri dari beberapa komponen berupa beberapa bagian dari suatu sistem atau subsistem. Sistem ini mempengaruhi manajemen lembaga pendidikan sampai batas tertentu. Batasan sistem membatasi batas antara suatu sistem dan sistem lain serta lingkungan luarnya. Batasan sistem memungkinkan sistem dianggap sebagai satu kesatuan. Batas sistem menunjukkan kisaran atau kisaran tertentu dari sistem.

\section{Pengaruh / Hubungan Pendanaan Terhadap Manajemen Lembaga Pendidikan Islam}

Hal ini dapat di jelaskan bahwa Anggaran biaya pendidikan terdiri dari dua sisi yang berkaitan satu sama lain, yaitu sisi anggaran penerimaan dan anggaran pengeluaran untuk mencapai tujuan-tujuan pendidikan. Untuk sekolah dasar negeri, umumnya memiliki sumbersumber anggaran penerimaan, yang terdiri dari pemerintah pusat, pemerintah daerah, masyarakat sekitar, orang tua murid, dan sumber lain.(Indonesia \& Sekolah, 2018). Berdasarkan pendekatan unsur biaya (ingredient approach), pengeluaran sekolah dapat dikaegorikan ke dalam beberapa item pengeluaran, yaitu; Pengeluaran untuk pelaksanaan pelajaran, Pengeluaran untuk tata usaha sekolah, Pemeliharaan sarana dan prasarana sekolah, Kesejahteraan pegawai, Administrasi, Pembinaan teknis educative.

Di Indonesia, kelompok masyarakat membangun dan mengoperasikan banyak sekolah atau lembaga pendidikan negeri dan swasta. Sedangkan untuk masyarakat biasanya menggalang dana untuk lembaga pendidikan dalam hal pengembangan sekolah, berpartisifasi dalam hal membangun sekolah, mencari donatur dan dermawan baik mengikat maupun tidak mengikat (Luneto, 2015).

Pendanaan pendidikan Islamsangat berpengaruh terhadap manajemen lembaga pendidikan Islam. Dan ini sudah banyak di teliti oleh peneliti sebelumnya di antaranya adalah (Cherrry, 2010), (W. P, 2013), (Usman, 2017), (Idris, 2010).

\section{Kerangka Konseptual}

Berdasarkan rumusan masalah penulisan artikel ini dan kajian studi literature review baik dari buku maupun artikel yang relevan, maka dapat di perolah kerangka artikel yang bertema faktor yang mempengaruhi manajemen pendidikan Islam, seperti di bawah ini. 


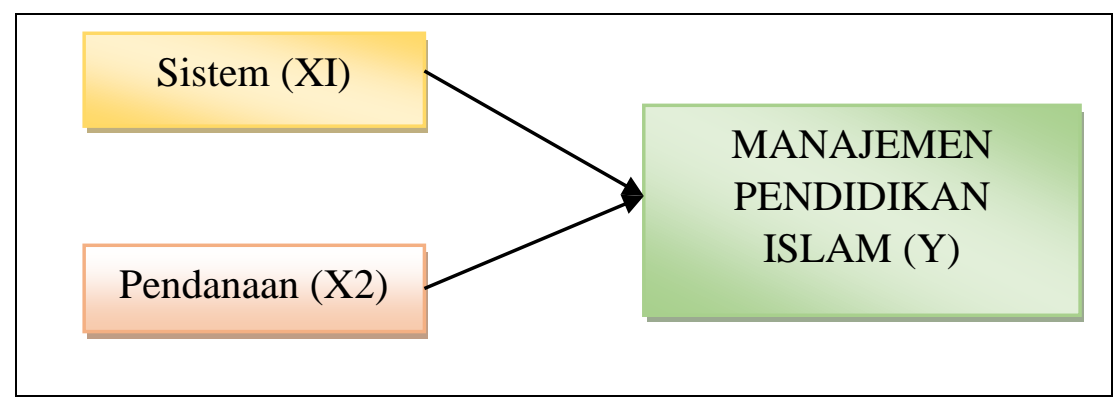

Gambar 1: Kerangka Konseptual

Berdasrakan kajian teori, review hasil riset dari jurnal yang relevan serta gambar dari kerangka konseptual maka dapat di rumuskan hipotesis untuk riset selanjutnya:

1). Sistem berpengaruh terhadap manajemen pendidikan Islam

2). Pendanaan berpengaruh terhadap manajemen pendidikan Islam

\section{KESIMPULAN DAN SARAN}

\section{Kesimpulan}

Berdasarkan rumusan artikel, hasil dan pembahasan yang di kaji dan di bahas pada artikel ini, maka dapat disimpulkan untuk membangun suatu hipoteis guna untuk riset selanjutny aadalah:

1) Sistem berpengaruh terhadap manajemen pendidikan Islam

Suatu sistem sangat mempengaruhi berkembangnya suatu instansi, terkhususnya di dalam manajemen suatu organisasi. Dan sistem terdiri dari sejumlah komponen yang saling berhubungan satru sama lain, yang berarti saling berkerjasama untuk membentuk suatu kesatuan. Guna mewujudkan hasil yang efektif dan efisien.

2) Pendanaan berpengaruh terhadap manajemen pendidikan Islam

Konsep biaya pendidikan adalah seluruh pengeluaran baik yang berupa uang maupun bukan uang sebagai ungkapan rasa tanggung jawab semua pihak yakni masyarakat, orangtua, dan pemerintah terhadap pembangunan pendidikan agar tujuan serta cita-cita yang sudah ditentukan bisa tercapai secara efektif dan efisien. Selanjutnya biaya pendidikan harus digali dari berbagai sumber, dipelihara, dikonsolidasikan, dan ditata secara administratif sehingga dilaksanakan secara efektif dan efisien.

\section{Saran}

Bersdasarkan Kesimpulan di atas, maka saran pada artikel ini adalah bahwa masih banyak faktor lain yang mempengaruhi manajemen pendidikan islamselain dari sistem pendanaan. Seperti faktor kebijakan pemerintah, faktor budaya, faktor sumber daya manusia, dan faktor-faktor lainya pada semua tipe dan level lembaga atau organisasi yang dapat mempengaruhinya. Oleh karena itu masih di perlukan kajian yang lebih lanjut untuk mencari faktor-faktor lain apa saja yang dapat memepengaruhi pendidikan islam selain yang di teliti pada artikel ini. 


\section{DAFTAR RUJUKAN}

Ackoff, R. L. (1994). Systems thinking and thinking systems. System Dynamics Review. https://doi.org/10.1002/sdr.4260100206

Ali, H., \& Limakrisna, N. (2013). Metodologi Penelitian ( Petunjuk Praktis Untuk Pemecahan Masalah Bisnis, Penyusunan Skripsi, Tesis, dan Disertasi. In Deeppublish: Yogyakarta.

ARIFIN, M. (2017). Manajemen Keuangan Pondok Pesantren. FIKROTUNA. https://doi.org/10.32806/jf.v4i2.2745

Atmaja, T. E. R., Harun, C. Z., \& Ibrahim, S. (2016). Analisis Penetapan Standar Biaya Pendidikan. Jurnal Administrasi Pendidikan.

Bangun, R., Informasi, V., Achievement, S., Berlangganan, T. V, Sistem, M., Di, D., Regional, T., \& Bali, O. (2014). Jurnal Sistem Informasi. Sistem Informasi.

BARIDWAN, Z. (2015). Pengertian Sistem. Zaki Baridwan.

Cherrry, A. (2010). Makalah Tentang Permasalahan Pendidikan di Indonesia. In Permasalaham Pendidikan di Indoneia.

Fadhli, M. (2017). Manajemen Peningkatan Mutu Pendidikan. Tadbir: Jurnal Studi Manajemen Pendidikan. https://doi.org/10.29240/jsmp.v1i2.295

Fattah, N. (2016). Landasan Manajemen Pendidikan. In Bandung: Remaja Rosdakarya.

Hasibuan, A. A., Syah, D., \& Marzuki, M. (2018). MANAJEMEN PENDIDIKAN KARAKTER DI SMA. Tarbawi: Jurnal Keilmuan Manajemen Pendidikan. https://doi.org/10.32678/tarbawi.v4i02.1230

Hidayatno, A. (2016). Berpikir Sistem: Pola Berpikir untuk Pemahaman Masalah yang lebih baik. ResearchGate.

Husaini, U. (2008). Manajemen: Teori, Praktik dan Riset Pendidikan. In SCMS Journal January-March 2008.

Idris, M. (2008). PENDANAAN PENDIDIKAN ISLAM: SEBUAH TINJAUAN HISTORIS. Lentera Pendidikan: Jurnal Ilmu Tarbiyah Dan Keguruan. https://doi.org/10.24252/lp.2008v11n2a2

Idris, R. (2010). APBN PENDIDIKAN DAN MAHALNYA BIAYA PENDIDIKAN. Lentera Pendidikan: Jurnal Ilmu Tarbiyah Dan Keguruan. https://doi.org/10.24252/lp.2010v13n1a7

Indonesia, U. P., \& Sekolah, M. (2018). Manajemen Pembiayaan Pendidikan Terhadap Mutu Sekolah Menengah Kejuruan. Jurnal Penelitian Pendidikan.

Kristiawan, M., Safitri, D., \& Rena Lestari. (2017). Manajemen Pendidikan. Deepublish.

Kuntoro, A. T. (2019). Manajemen Mutu Pendidikan Islam. Jurnal Kependidikan. https://doi.org/10.24090/jk.v7i1.2928

Luneto, B. (2015). Manajemen Pembiayaan Pendidikan di Madrasah. Tadbir; Jurnal Manajemen Pendidikan Islam.

Madarik, M. (2018). MANAJEMEN MADRASAH DALAM PERSPEKTIF ISLAM. CENDEKIA : Jurnal Studi Keislaman. https://doi.org/10.37348/cendekia.v2i1.25

Mochammad Arif Budiman. (2017). Pendidikan Agama Islam. Banjarbaru: Grafika Wangi Kalimantan.

Mujilan, A. (2013). Analisis Dan Perancangan Sistem. Universitas Widya Mandala Madiun.

Nasution, S. (2002). Metode Penelitian. Jakarta: Rineka Cipta.

Purnomo, D. (2015). Pembiayaan pendidikan. Pendidikan Ekonomi.

Rahmah, N. (2016). Prinsip-Prinsip Manajemen Keuangan Sekolah. Kelola: Journal of Islamic Education Management. https://doi.org/10.24256/kelola.v1i1.430

Romlah. (2016). Manajemen Pendidikan Islam. Journal of Chemical Information and Modeling, 178. http://repository.radenintan.ac.id/id/eprint/3317

Romney, M. B., \& Steinbart, P. J. (2015). Pengertian sistem menurut Marshall B Romney 
dan Paul John Steinbart. In Sistem Informasi Akuntansi.

Salamun. (2017). SISTEM MONITORING NILAI SISWA BERBASIS ANDROID. : : Jurnal Teknologi Dan Sistem Informasi Univrab, 2(2), 99-109.

Siti Zakiah Binti Ali, \& Hairunnizam Wahid. (2014). Peranan dan Kepentingan Dana Wakaf Institusi Pendidikan Tinggi di Malaysia. Persidangan Kebangsaan Ekonomi Malaysia $\mathrm{Ke}-9$.

Suharsimi, A. (2013). Metodologi penelitian. In bumi aksara.

Sulindawati, \& Fathoni, M. (2010). Pengantar Analisa Perancangan " Sistem “. Jurnal Saintikom.

Sumarto. (2016). BERPIKIR KESISTEMAN DALAM MENGATASI PERMASALAHAN LEMBAGA PENDIDIKAN ISLAM (STUDI MASALAH DI KOTA JAMBI). Pengaruh Harga Diskon Dan Persepsi Produk Terhadap Nilai Belanja Serta Perilaku Pembelian Konsumen, 1(31-50), 27-44.

Syahminan. (2014). MODERNISASI SISTEM PENDIDIKAN ISLAM DI INDONESIA PADA ABAD 21. Ilmiah Peuradeun, II(2), 235-260. https://journal.scadindependent.org/index.php/jipeuradeun/article/view/35

Tedjawati, J. M. (2013). Pendanaan Pendidikan Anak Usia Dini. Jurnal Pendidikan Dan Kebudayaan. https://doi.org/10.24832/jpnk.v19i3.294

Tho'in, M. (2017). Pembiayaan Pendidikan Melalui Sektor Zakat. Al-Amwal: Jurnal Ekonomi Dan Perbankan Syari'ah. https://doi.org/10.24235/amwal.v9i2.1794

Usman, J. (2017). URGENSI MANAJEMEN PEMBIAYAAN DALAM PENINGKATAN MUTU PENDIDIKAN MADRASAH. TADRIS: Jurnal Pendidikan Islam. https://doi.org/10.19105/tjpi.v11i2.1170

W. P, F. (2013). Pembiayaan Pendidikan: Suatu Kajian Teoritis. Jurnal Pendidikan Dan Kebudayaan. https://doi.org/10.24832/jpnk.v19i4.310 